\title{
POR QUE MATAMOS O BARBEIRO? REFLEXÕES PRELIMINARES SOBRE A PARADOXAL EXCLUSÃO DO OUTRO*
}

\author{
Regina Maria de SouZA* \\ SILVIO GALLO ${ }^{* * *}$
}

\begin{abstract}
Não é um paradoxo dizer que nos nossos momentos de inspiração mais teórica podemos estar o mais próximo possível de nossas questões mais práticas.
\end{abstract}

(Alfred Whitehead)

RESUMO: Este trabalho discutirá a exclusão como efeito de mecanismos ao mesmo tempo assimilatório e racista. Racismo é aqui entendido como efeito de um processo que coloca em jogo tanto o temor subjetivo de se haver com o desejo do outro/estranho a mim mesmo como, também, uma fina rede de poderes articulados. Esta reflexão terá como objetivo iniciar, ainda que timidamente, um diálogo com Michel Foucault e autores inscritos na psicanálise. Isso será feito não no sentido de mostrar a possibilidade de, entre os conjuntos teóricos que representam, haver qualquer ponto de interseção, mas no sentido de apontar a necessidade de ser fabricada uma ferramenta que possa explicar a "colagem" dos dispositivos de poder ao funcionamento do sujeito, que, via de regra, deixa-se capturar por eles.

Palavras-chave: (A)Normalidade. Michel Foucault. Estrangeiro. Estranho. Desejo. Sigmund Freud.

Este artigo foi produzido por solicitação do prof. Alfredo Veiga-Neto que, em novembro de 2001, esteve na Faculdade de Educação da Universidade Estadual de Campinas (UniCAMP) para ministrar o workshop: "O (a)normal e o patológico em Michel Foucault" (Sol. Faep no 0874/ 01). De muitas maneiras diferentes, a presente reflexão reativa discussões iniciadas naquela ocasião e faz retornar a sua presença.

** Professora da Faculdade de Educação da Universidade Estadual de Campinas (Unicamp). E-mail: monobere@unicamp.br.

*** Professor da Faculdade de Educação da Universidade Estadual de Campinas (UniCAmP) e da Faculdade de Filosofia, História e Letras da Universidade Metodista de Piracicaba (UnimeP). E-mail: gallo@unicamp.br. 
WHY DO WE KILL THE BARBER?

PRELIMINARY REFLECTIONS ON THE PARADOXICAL EXCLUSION OF THE OTHER

ABSTRACT: This paper discusses exclusion as the effect of mechanisms that are at the same time assimilatory and racist. Racism is here understood as the effect of a process involving both the subjective fear of dealing with the desire of the other/stranger and a fine network of articulated powers. The aim of this reflection is to initiate a dialogue, however timid, with Michel Foucault as well as with authors who recur to a psychoanalytic approach. The intent is not to demonstrate there may have any points of intersection among the various theoretical groups they represent, but rather to point out the need to fashion a tool that explains the bonding of mechanisms of power to the subject's functioning, subject who usually lets himself be entangled by them.

Key words: (Ab)Normality. Michel Foucault. Psychoanalysis. Strange. Foreign. Sigmund Freud. Desire.

\section{Sobre as condições de produção deste artigo}

O progresso, como o andar, consegue-se perdendo e ganhando equilíbrio. (FreUd)

$\mathcal{N}$ o dia 3 de abril de 2002, os senadores aprovaram a emenda da Câmara relativa ao projeto de Benedita da Silva, reconhecendo como meio legal de comunicação e expressão de comunidades surdas do pais a língua brasileira de sinais (libras). No dia $11 \mathrm{de}$ abril, circulou na Internet um abaixo-assinado, destinado àqueles senadores, elaborado por um grupo de surdos autodenominados "surdos oralizados", que insistiam na idéia de que "somente a oralização amplia nossas capacidades e iniciativas como qualquer ser humano" (grifo nosso) e, por isso, enfatizavam "que somente o oralismo é capaz de, como um todo, nos incluir na sociedade". Os autores do abaixo-assinado compararam a libras ao latim, metáfora que ativa a memória de língua morta, sistema sem território de inscrição e sem usuários vivos. Texto que cria o efeito de um racismo surdo contra o outro surdo.

Em 15 de abril, Souza, autora deste artigo, participou de uma banca de qualificação em que a pesquisadora surda Perlin (2002) defendia a tese de que na tensão das relações sociais mediadas pela libras, no interior das comunidades surdas e no confronto entre elas e as nossas ouvintes, as pessoas surdas constituíam identidades outras que não 
aquelas descritas para elas por experts ouvintes. Uma das mais conhecidas formas de inscrição dessas alteridades, realizada por especialistas, traduzse em colocá-las no espaço geométrico destinado aos artefatos danificados do padrão considerado normal para a espécie humana. ${ }^{1}$

A defesa do projeto por Perlin colocou-nos algumas questōes, entre elas, como entender esses outros surdos não oralizados, que insistem em marcar conosco uma estrangeirice, uma diferença radical em termos sociais, culturais e identitários? ${ }^{2}$

Se, como pressuposto, considerarmos que o normal para a espécie humana é ouvir e falar, os surdos, seja como se queiram narrar, serão sempre uma diversidade, subconjuntos de pontos na superfície de um gráfico que gradua diferenças audiométricas - uma diferença para menos nos valores pontuados pela curva do sino.

Entretanto, se quiséssemos pensar para além dos limites geométricos da norma, se decidíssemos escutar, e não contestar, o que Perlin defendia, como entender sua diferença? E como explicar o fato de ela sua suposta estrangeirice - nos ser tão perturbadoramente estranha $\left(\right.$ unheimlich $^{3}$ )? Como entender essa alteridade estrangeira em uma população politicamente definida como sendo a de um único povo brasileiro?

Dado que a norma é uma entidade geométrica, julgamos que seria interessante buscarmos outra metáfora na matemática para entendermos a questão. Assim sendo, nos preocupamos em encontrar uma noção que se relacionasse com a possibilidade da existência, em um conjunto de elementos que não pertencessem à norma geral da população da qual, todavia, faziam parte. ${ }^{4}$ Essa busca nos levou ao paradoxo de Russell. ${ }^{5}$

\title{
O paradoxo de Bertrand Russell
}

\author{
La frontière cést une invention des hommes. La nature s'en \\ fout. (Palavras finais de J. Gabin no filme $A$ grande ilusão, \\ de Jean Renoir) ${ }^{6}$
}

A formulação do paradoxo de Russell foi possível, em certo sentido, como decorrência da elaboração, por Cantor, de sua "teoria abstrata de conjunto", na qual rompe com a restrição aristotélica sobre 
a forma de ser das finitudes e estabelece definições operativas como a de potência (Rezende, 2002, p. 5). Tais definiçôes, por sua vez, ofereceram o horizonte discursivo necessário para que pudessem ser formuladas asserçóes impredicativas em paradoxos, como o fez Russell, ao definir "como $\mathrm{W}$ o conjunto dos conjuntos que não pertencem a si mesmos" (idem, p. 19). ${ }^{7}$

A antinomia de Russell traz implícita a possibilidade lógica da existência, em uma população, de elementos que, apesar de pertencerem a ela, não fazem parte, paradoxalmente, dela mesma. Portanto, seria legítimo supor, por derivação, que não estariam sujeitos à mesma norma do conjunto do qual fariam parte.

Mantendo o raciocínio lógico desse paradoxo, talvez pudéssemos afirmar que um elemento estranho deveria, pois, pertencer ao conjunto, ser parte constitutiva dele, ser um elemento logicamente necessário ao todo - embora, vale enfatizar, paradoxalmente, extraneus a ele.

Essa noção de conjunto, em que estamos nos inspirando, faz remessa, igualmente, à noção de fronteira, entendida, não necessariamente, no estrito sentido geopolítico. Trata-se, antes, de uma fronteira interna que separa um conjunto de pessoas no interior de um mesmo país, não importando se tenham, ou não, uma localização territorial estável ou demarcável. Isso porque os elementos de um conjunto podem ter uma distribuição aleatória, do ponto de vista espacial, nos limites desse mesmo conjunto. Por derivação, novamente, poderíamos afirmar que o fremd ${ }^{8}$ pode morar ao nosso lado.

Vive na casa vizinha e goza de maneira diferente. É justamente aí que reside o problema. Aquilo que era tolerável quando o estrangeiro estava longe, torna-se insuportável a partir do momento em que ele se aproxima demais e nos impóe suas "excentricidades". (Koltai, 2000, p. 117-118)

Devemos enfatizar, neste ponto, que nossa intenção não é discutirmos as repercussões que a antinomia de Russell exerceu sobre os fundamentos da matemática moderna, ou fazermos uma análise sobre as possíveis ingenuidades conceituais que ajudaram a fabricar. Vamos, sim, realizar um uso interesseiro desse paradoxo e nele nos inspirar para criar uma fábula que deslocará a questão das disputas na área da surdez (por exemplo) para as questôes de fundo que, a nosso ver, oferecem o substrato de abrigo àqueles imbróglios. 
De que maneira um discurso da razão poderia falar disso (ça)?" (FoucAulT)

Em algum lugar haverá uma cidade que chamaremos de A. Nela, todas as pessoas cortam o cabelo no mesmo barbeiro (B). Portanto, W poderia ser considerado o conjunto de todas as pessoas que, morando em A, cortam o cabelo com B. Estranha situação a de B: ele é a única pessoa que, embora nativo da cidade, não corta o cabelo consigo mesmo e, portanto, não pode, ao menos por definição, pertencer ao conjunto W, do qual todos os seus demais compatriotas fazem parte. Aliás, ele nunca havia cortado o cabelo. Como Guer do Antigo Testamento, ${ }^{10}$ ele insistia em sua diferença. Entretanto, dividia alegrias e sofrimentos com aqueles que solicitavam seus serviços. Ah! Sim, havia uma interdição que ele, delicadamente, impunha: ele jamais se narrava ou se contava como mais um entre os demais...

$\mathrm{Na}$ clausura desse silêncio ia, pouco a pouco, convertendo-se em estrangeiro. Nada se sabia de sua vida pregressa, quando teria nascido, se seria casado, que doenças teria tido, a quem haveria amado, o que teria acumulado de conhecimentos sobre a vida, que saberes eram esses, etc. B insistia apenas em compartilhar a dádiva que era viver o presente. Por outro lado, todos os demais, como sói ocorrer com freqüentadores de barbeiros, confidenciavam-lhe segredos, medos, pavores e toda a sorte dessas quinquilharias vividas, desejadas ou temidas no dia-a-dia de vidas tediosas, e previsivelmente normais. Ele era assim como um sujeito bricolage, fragmentos múltiplos de todos em sua escuta.

Desse modo, cada um que cortava o cabelo em B podia nele se ver como uma espécie de imagem refletida no espelho - tornou-se B, sem querer, ou sem que tivesse consciência, um duplo desse outro que nele se confessava, que se mostrava, desavergonhadamente, em seus cantos mais emudecidos e escuros. Aos poucos, o silêncio da escuta tornou-se ameaçador. Um dia, B apareceu morto - inúmeras incisões atravessavamlhe o corpo.

O Estado, por meio da Delegacia Civil, acabou por encerrar o caso por falta de provas que conduzissem a um mesmo e único suspeito (ou pelo menos ao golpe fatal). E cada pessoa, de modo constrangido e cúmplice, silenciou-se definitivamente em relação à morte do barbeiro, e de algum modo, à morte de si mesma. 
Entretanto, em noites frias e longas de inverno, cada um, em sua cama, acabava por se perguntar: Por que matamos o barbeiro?

A fim de nos haver com essa questão, vamos considerar duas vertentes de discussão: uma de natureza política e social e outra de natureza afetiva. Entre todas as escolhas possíveis, os autores optaram por, no primeiro caso, enveredar pelos escritos de Michel Foucault e, no segundo caso, de Freud e outros autores da psicanálise. Foucault oferece-nos ricas ferramentas para entendermos, por exemplo, os elementos que articulam o racismo de Estado (e a morte do barbeiro como decorrência). Freud e seguidores oferecem explicações elegantes sobre a perturbação que gera a presença do estranho/estrangeiro entre/ em nós.

Não se trata, aqui, de buscarmos pontos de contato entre duas abordagens que, mais apropriadamente, talvez possam ser representadas sob a forma de paralelas - linhas de pensamento condenadas a jamais se encontrarem. Mas sim o exercício de uma primeira mirada que nos permita considerar por quais aspectos cada uma delas nos franquearia o entender da questão-título, se tomadas na condição de retas singulares. Mais especificamente, como com base nelas poderíamos entender o (a)normal e o estranho.

Poder disciplinar, biopoder e norma:

elementos de um racismo de Estado

O progresso e aperfeiçoamento da matemática estão intimamente ligados com a prosperidade do Estado.

(NAPOLEĀO I)

Entre 7 de janeiro e 17 de março de 1976, Michel Foucault ofereceu um curso, no Collège de France, com o título Il Fault Défendre la Societé. ${ }^{11} \mathrm{O}$ tema desse curso é o poder, seu exercício, seus efeitos. O filósofo investe na idéia de que é possível construir toda uma imagem positiva do poder e de seus efeitos e é isso que Foucault desenvolveria no primeiro volume da História da sexualidade, publicado nesse mesmo ano de 1976. Já na primeira aula, o objetivo central de Foucault é o de contrapor dois grandes sistemas de análise do poder, um voltado para a noção de soberania, que redunda necessariamente em uma noção de poder como opressão, derivada do contrato político, ao passo que um segundo sistema poderia ser formulado a partir do par guerra-repressão. 
Se a opressão é um abuso do poder, a repressão, em contrapartida, nada mais é do que um de seus efeitos.

À noção de que o mecanismo de exercício do poder seria a repressão, Foucault chama de "hipótese de Reich"; à noção de que ele é resultado de um enfrentamento de forças, ele chama de "hipótese de Nietzsche". É essa segunda hipótese que Foucault exercita em suas análises, sobretudo aquelas que trouxeram à luz a emergência de um poder disciplinar.

Mas, nesse curso, Foucault vai analisar a emergência de um outro poder: aquele que se exerce sobre a vida, sobre o humano como ser vivo, um movimento de estatização do biológico. Enquanto a soberania se ocupava em "fazer morrer" ou "deixar viver", esse novo mecanismo de poder vai se ocupar de "fazer viver" e "deixar morrer". A ele, Foucault chamará de biopoder.

O biopoder não se opõe ao poder disciplinar, mas são tecnologias de poder complementares. Se a disciplina como tecnologia de poder se instala já no final do século XVII e consolida-se ao longo do século XVIII, o biopoder emerge durante a segunda metade desse mesmo século XVIII. Se o poder disciplinar é uma tecnologia centrada no corpo e, portanto, um mecanismo de individualização, o biopoder aparece como uma tecnologia exercida sobre a vida, sobre a espécie e não sobre o indivíduo, constituindo-se num mecanismo de massificação. Neste aspecto, a biopolítica retoma a disciplina, integra-a, engloba-a, ressignifica-a.

Uma tecnologia de poder que não exclui a primeira, que não exclui a técnica disciplinar, mas que a embute, a integra, que a modifica parcialmente e que, sobretudo, vai utilizá-la implantando-se de certo modo nela, e incrustando-se efetivamente graças a essa técnica disciplinar prévia. Essa nova técnica não suprime a técnica disciplinar simplesmente porque é de outro nível, está noutra escala, tem outra superfície de suporte e é auxiliada por instrumentos totalmente diferentes. (Foucault, 2000, p. 288-289)

Da mesma maneira que a tecnologia do poder disciplinar tem como objeto a sujeição do corpo do indivíduo, tornando-o dócil, manipulável, a tecnologia do biopoder é exercida sobre um corpo, mas não um corpo individual e sim coletivo. Esse novo corpo político, distinto do corpo individual e do corpo social, a um só tempo instituído por e objeto sobre o qual o biopoder se exerce, é a população. Nas palavras de Foucault, "A biopolítica lida com a população, e a população como problema político, como problema a um só tempo científico e político, como problema biológico e como problema de poder, acho que aparece nesse momento" (ibid., p. 292-293). 
$\mathrm{Na}$ sociedade sob a égide da biopolítica, trata-se de controlar a população, de modo que se estabelecem mecanismos de se acompanhar e controlar a proporção de nascimentos e óbitos, a taxa de reprodução, de se efetuar o controle de endemias e epidemias que se abatem sobre uma dada população etc. Como se trata de "fazer viver" e, em determinados casos, "deixar morrer", a biopolítica faz nascer sistemas de seguridade social, de previdências públicas e privadas, de poupanças. Em suma, podemos dizer que a própria noção de Estado de bem-estar social só foi possível sob a égide do biopoder.

Embora a biopolítica seja complementar à disciplina e não antagônica a ela, sua emergência ainda no final do século XVIII levaria a uma nova forma de organização social, para além da disciplinar, que só começaria a ser delineada na segunda metade do século XX. Foucault vislumbrou a sua emergência, mas foi Deleuze (num pequeno texto escrito em 1990) quem a nomeou e iniciou sua análise: as sociedades de controle.

Encontramo-nos numa crise generalizada de todos os meios de confinamento, prisão, hospital, fábrica, escola, família (...). Os ministros competentes não param de anunciar reformas supostamente necessárias. Reformar a escola, reformar a indústria, o hospital, o exército, a prisão; mas todos sabem que essas instituições estão condenadas, num prazo mais ou menos longo. Trata-se apenas de gerir sua agonia e ocupar as pessoas, até a instalação das novas formas que se anunciam. São as sociedades de controle que estão substituindo as sociedades disciplinares. "Controle" é o nome que Burroughs propõe para designar o novo monstro, e que Foucault reconhece como nosso futuro próximo (...). Não se deve perguntar qual o regime mais duro, ou o mais tolerável, pois é em cada um deles que se enfrentam as liberações e as sujeiçōes. Por exemplo, na crise do hospital como meio de confinamento a setorização, os hospitais-dia, o atendimento em domicílio puderam marcar de início novas liberdades, mas também passaram a integrar mecanismos de controle que rivalizam com os mais duros confinamentos. (Deleuze, 1992, p. 220)

Seguindo as trilhas de Foucault (2000) e Deleuze (1992), Antonio Negri e Michael Hardt (2001) utilizaram-se das noções de biopoder e de sociedades de controle para analisar a forma atual da política, que eles chamam de império.

Devemos entender a sociedade de controle (...) como aquela (que se desenvolve nos limites da modernidade e se abre para a pós-modernidade) na qual mecanismos de comando se tornam cada vez mais "democráticos", cada vez mais imanentes ao campo social, distribuídos por corpos e cérebros dos cidadãos (...). A sociedade de controle pode, dessa forma, ser caracterizada por uma intensificação e uma síntese dos aparelhos de normalização de disciplinaridade que animam interna- 
mente nossas práticas diárias e comuns; mas, em contraste com a disciplina, esse controle estende bem para fora os locais estruturados de instituiçóes sociais mediante redes flexíveis e flutuantes. (Negri e Hardt, 2001, p. 42-43)

Voltando a Foucault e a seu curso de 1976, percebemos que, se a disciplina opera com uma série corpo-organismo-disciplina-instituições, o biopoder opera por meio da série população-processos biológicosmecanismos regulamentadores-Estado. Ora, se a disciplina opera no nível do detalhe, do corporal, do individual, por intermédio das instituições, o biopoder opera num nível mais global, atravessando as populações, por meio do Estado. De outro lado, se a disciplina opera pela instituição da norma, a biopolítica opera pela regulamentação. A articulação normaregulamentação fica bastante evidente em certos casos, como o da sexualidade, que a partir do século XIX se torna de importância estratégica:

De um lado, a sexualidade, enquanto comportamento exatamente corporal, depende de um controle disciplinar, individualizante, em forma de vigilância permanente (...) e depois, por outro lado, a sexualidade se insere e adquire efeito, por seus efeitos procriadores, em processos biológicos amplos que concernem não mais ao corpo do indivíduo mas a esse elemento, a essa unidade múltipla constituída pela população. A sexualidade está exatamente na encruzilhada do corpo e da população. Portanto, ela depende da disciplina, mas depende também da regulamentação. (Foucault, 2000, p. 300)

Até o momento estivemos acompanhando Foucault em sua análise da biopolítica como exercício de um poder de "fazer viver"; mas como fica o lado do "deixar morrer"? É aí que se inscreve o problema do racismo de Estado, e aquilo que realmente importa em nossa presente análise. $\mathrm{Na}$ analítica foucaultiana, o racismo é o mecanismo pelo qual o Estado justifica seu direito de matar, numa sociedade biopolítica, fundada na afirmação da vida. E o que é mais interessante: o direito de matar é justificado como uma afirmação da própria vida, uma vez que a eliminação do diferente, do menos dotado, do menos capaz implica a purificação da raça, o melhoramento da população como um todo. A cada um que morre, o conjunto resultante é melhor que o anterior. $\mathrm{O}$ racismo de Estado é, pois, a feição moderna do evolucionismo e do darwinismo social novecentista. (2000):

Como ele emergiu? Acompanhemos o raciocínio de Foucault

Retomando, reciclando a forma, o alvo e a própria função do discurso sobre a luta das raças, mas deturpando-os, esse racismo se caracterizará pelo fato de que 
o tema da guerra histórica - com suas batalhas, suas invasões, suas pilhagens, suas vitórias e suas derrotas - será substituído pelo tema biológico, pósevolucionista, da luta pela vida. Não mais batalha no sentido guerreiro, mas luta no sentido biológico: diferenciação das espécies, seleção do mais forte, manutenção das raças mais bem adaptadas etc., assim, também, o tema da sociedade binária, dividida entre duas raças, dois grupos estrangeiros, pela língua, pelo direito etc., vai ser substituído pelo de uma sociedade que será, ao contrário, biologicamente monista (...). Enfim, o tema do Estado, que era necessariamente injusto na contra-história das raças, vai se transformar em tema inverso: o Estado não é o instrumento de uma raça contra uma outra, mas é, e deve ser, o protetor da integridade, da superioridade e da pureza da raça. (Ibid., p. 94-95)

Foucault destaca que a emergência do racismo no contexto da biopolítica desempenha duas funções fundamentais. De um lado, introduz um corte, por meio da regulamentação: define a separação entre aquele que deve viver e aquele que deve morrer. De outro lado, inscreve a velha função guerreira no embate entre os indivíduos no contexto da biologia. Em outras palavras, institui uma relação biológica, para além da relação militar e da relação política. Aquele que deve viver não é o mais corajoso, mais forte, ou mais politicamente hábil; o que deve viver é o mais puro, o "mais superior", o mais sadio. A afirmação de sua vida e a eliminação de seu outro (isto é, o impuro) são a afirmação de toda a raça, são a afirmação de uma população mais sadia.

Um outro elemento importante para o racismo é que o impuro, aquele que deve morrer, não se encontra necessariamente "fora" do conjunto, fora do Estado, isto é, o impuro não é o estrangeiro por excelência, mas pode estar aqui mesmo, entre nós. A guerra de extermínio dos nazistas contra os judeus - provavelmente o melhor exemplo deste racismo de Estado - não era uma guerra contra os que se encontravam fora, mas contra os judeus alemães, depois contra os judeus de todos os territórios dominados pela Alemanha. Exterminar os judeus - que podiam ser os vizinhos do lado - significava não apenas eliminar a impureza racial, mas, mais do que isso, implicava também purificar a raça ariana.

O racismo de Estado consiste, portanto, numa forma de regulamentação que está muito além do poder disciplinar. Enquanto a tecnologia e os mecanismos disciplinares operam com a normalização, definindo aqueles que se encontram na norma ou fora dela, procurando normalizar os anormais, a tecnologia biopolítica opera com a eliminação do degenerado, do inferior. Nesse sentido, o exercício do racismo é o de um apagamento das diferenças. Primeiramente, ele opera uma divisão na 
espécie, separando-a em raças. Afirmou Foucault que "essa é a primeira função do racismo: fragmentar, fazer cesuras no interior desse contínuo biológico a que se dirige o biopoder" (2000, p. 305). Em segundo lugar, exercita e dissemina o ódio entre as raças, sobretudo o ódio pelo inferior (ódio esse que, hobbesianamente, funda-se no medo do outro, em vê-lo como ameaça - à pureza, saúde etc. - da raça superior); por fim, promove o extermínio da raça inferior, de modo que se garanta a saúde da raça superior e a sua evolução.

No contexto do poder disciplinar, a convivência com o diferente ainda é possível. Claro que se trata, de toda forma, de tentar trazê-lo para o âmbito do mesmo, de partir da constatação da diferença, como desvio da norma, para em seguida discipliná-lo, colocá-lo na norma, ou pelo menos dentro de um desvio-padrão "aceitável". Mas, no reino do biopoder, a diferença é por demais nociva, e precisa ser eliminada. Mais que isso, ela cumpre uma "função social" de garantir a legitimidade do Estado em promover a morte, de modo que se garanta a sanidade social.

Foucault salienta que o racismo não é um fenômeno recente, sendo comum em outros períodos; a novidade é que no contexto da biopolítica ele é exercido como uma função do Estado, uma forma de regulamentação social.

A especificidade do racismo moderno, o que faz sua especificidade, não está ligado a mentalidades, a ideologias, a mentiras do poder. Está ligado à técnica do poder, à tecnologia do poder. Está ligado a isto que nos coloca, longe da guerra das raças e dessa inteligibilidade da história, num mecanismo que permite ao biopoder exercer-se. Portanto, o racismo é ligado ao funcionamento de um Estado que é obrigado a utilizar a raça, a eliminação das raças e a purificação da raça para exercer seu poder soberano. (Ibid., p. 309)

No tocante ao aspecto político e social da morte do barbeiro, a noção de biopoder e sua tecnologia do racismo são importantes ferramentas para respondermos à questão-título deste artigo. $\mathrm{Na}$ medida em que o barbeiro se faz outro, na medida em que ele é o outro de cada um daquela população - mas um outro que é estranhamente o mesmo, uma vez que carregava um pouco de cada um, das confidências que ouvia -, o barbeiro era o (a)normal, o colocado fora da norma, o único excluído do conjunto daqueles que cortavam o cabelo com ele. Mas ao mesmo tempo era estranhamente familiar...

Conviver com esse outro estranho - ao mesmo tempo tão familiar - não era tarefa fácil para os habitantes de A. Vemos operar aí a dupla instância do poder disciplinar e do biopoder. Por um lado, o barbeiro 
era o fora da norma, aquele que cortava o cabelo de todos, mas não o seu próprio. Até aí a convivência era possível. Mas, por outro lado, o barbeiro constituiu-se num estranho, aquele que carregava um pouco de cada um em si mesmo, sendo, no entanto, um outro. E aí a convivência já não era mais a mesma. É então que vemos operar a tecnologia do biopoder e o exercício de um racismo silencioso, que culmina na morte do barbeiro. Um racismo que se opera contra o diferente: aquele que tem os cabelos longos, ao passo que todos os outros os trazem curtos; aquele que exercita o silêncio, ao passo que os demais lhe fazem confidências. Em suma, um outro que é perigoso, que sabe demais. E um outro que é, ao mesmo tempo, visto como o inferior.

Essa foi uma morte que o Estado não se preocupou em resolver, sendo ela tão fundamental para sua manutenção, como exercício do "deixar morrer". Uma morte que pôs fim a uma incômoda diferença.

A psicanálise, por sua vez, oferecerá ferramentas para a compreensão da natureza afetiva da questão, ou seja, os motivos possíveis pelos quais o exercício de deixar o barbeiro morrer, pelo Estado, foi complementar ao subjetivo desejo de fazê-lo morrer por seus habitantes.

Sobre o estranho: o olhar da psicanálise

O efeito estranho da epilepsia e da loucura tem a mesma
origem. O leigo vê nelas a ação de forças previamente
insuspeitadas em seus semelhantes, mas ao mesmo tempo
está vagamente consciente dessas forças em remotas regiões
de seu próprio ser. ${ }^{12}$ (FREUD)

O termo estrangeiro deriva do latim extraneus que, como qualificativo, significa "vindo de fora". Mas foi apenas a partir do Império Romano que estrangeiro adquire conotação política. Até o século XIV, em francês a palavra estrange - que havia aparecido no século XII designava tudo aquilo que não era comum ou que não se oferecia à compreensão. No francês atual, étrange (estranho) faz parte da raiz de étranger (estrangeiro) - atributo tanto de quem é estranho como de quem vem do extérieur. No inglês do século XVI, strange dizia respeito tanto à mulher adúltera quanto aos elementos bastardos de uma família, ou, em outros termos, a tudo o que não fosse (reconhecidamente) familiar. Só depois do século XVIII passou a significar uma pessoa, objeto ou ser oriundo de outro país. No Oxford Advanced Learner's Dictionary lê-se que foreigner (estrangeiro) é uma pessoa de um lugar outro que não o seu 
país, ou alguém que não tenha vínculo de pertencimento a uma comunidade, a stranger or an outsider. Em alemão, fremd relacionava-se, primeiramente, ao não-familiar. $\mathrm{O}$ sentido de ser estrangeiro agregou-se, mais tarde, à palavra ausslander.

Consideremos assim que, do ponto de vista da língua, e por extensão do pensamento, o conceito de estrangeiro transformou-se de algo não-familiar em uma categoria sociopolítica, com tudo o que isto comporta. Seria analogismo exagerado pensar que algo semelhante acontece com o indivíduo? (Koltai, 2000, p. 23)

Em Cinco lições de psicanálise, Freud (1910/1970) afirma que o trauma, e sua conseqüente lembrança, age como um corpo estranho que, enquanto tal, produz o sintoma, ou cadeia de sintomas, simbolicamente alusivo(s) à situação traumática. O sintoma é, nesse sentido, o significante, a memória no corpo de um desejo/sentimento interditado. Para ele, o estranho era parte necessária do território psíquico.

Em O estranho (Unheimlich), Freud (1919/1976) faz um fascinante estudo da palavra unheimlich, buscando verificar as possibilidades de sua tradução em outras línguas. Para ele, em português, não haveria nenhum bom termo que pudesse traduzir o significado que teria em alemão. Todavia, afirma que em inglês há um termo bastante apropriado para ele - uncanny - termo negação de canny (arguto, prudente, precavido em assuntos de negócios, gentil, moderado, inofensivo) que pode, por seu turno, significar não apenas cosy (confortável, aconchegante) como algo misterioso, dotado de estranhos poderes. Uncanny refere-se, por sua vez, a algo não facilmente explicável, não-natural, não-familiar e levemente assustador.

O estranho é, antes de tudo, algo que se tornou unheimlich por ter sido antes familiar (heimlich) - a imagem no espelho que não é reconhecida como sendo eu mesmo, por exemplo. ${ }^{13}$

Se a teoria psicanalítica estiver correta, unheimlich é efeito de um material que retorna, um desejo que há muito foi interditado por repressão.

(...) se é essa na verdade, a natureza secreta do estranho, pode-se compreender por que o uso lingüístico estendeu das Heimlich [homely] (doméstico, familiar) para o seu oposto, das Unheimlich; pois esse estranho não é nada de novo ou alheio, porém algo que é familiar e há muito estabelecido na mente, e que somente se alienou desta através do processo de repressão. (Freud, 1976, p. 301) 
Lacan apresenta o estádio do espelho como um momento identitário inaugural em que a criança pôde reconhecer a si mesma, o que lhe exigiu a alienação de si à própria imagem refletida e, ao realizá-la, tornou a figura, que antes lhe mirava como se fosse um estranho, em eu mesma ${ }^{14}$ (Koltai, 2000). A identificação é, nestes termos, um processo que transforma o externo em interno (nascimento do eu) sendo o eu o lugar de desconhecimento.

Nesse sentido, para Lacan, está presente a função primordial do outro, aquela que colocará em jogo a dialética do desejo, em cuja dependência o sujeito se esforçará em advir. Lacan deixa claro que o que constitui o sujeito é justamente aquilo que o aliena, já que a formação do eu passa pela imagem do outro. $\mathrm{O}$ acesso da criança à sua imagem especular unificadora, totalizante, deve passar antes, inelutavelmente, pelo desejo do outro. (Koltai, 2000, p. 100)

O sujeito estará cativado por esse indecifrável desejo do/pelo Outro. ${ }^{15}$ E esse desconhecimento - a esfinge que toda alteridade é tanto gera a impossibilidade da realização do desejo - mantém a tensão de uma falta - como produz sentimentos ambivalentes de amor e ódio por este outro que não se deixa (re)conhecer.

A partir dessa hipótese, podemos supor que a morte do barbeiro poderia ser explicada como efeito de um intenso amor e ódio ao outro (ambivalência). E por isso sua exclusão definitiva foi tão desejada quanto temida ou perturbadora. Perturbadora porque cada pessoa, ao matar o barbeiro, matou, sem ter se dado conta, partes de si que haviam sido entregues a ele. Fazer surgir esses pedaços esquecidos e desejados impelia cada uma delas a entrar em um jogo de repetição permanente, metaforizado na insistente pergunta: Por que matamos $o$ barbeiro?

O barbeiro foi o personagem que entrou em cada uma daquelas vidas e aceitou que falassem de si; e elas, ao se entregarem a si mesmas com suas palavras, foram se tornando, pouco a pouco, textos vivos inscritos nele. Escritas e confissões de desejos transferidas de si mesmas para o corpo dele (palavras que se perdiam no labirinto dos ouvidos do homem desejado - onde estariam?). Um Ele silencioso que relutava em compartilhar dessa entrega. Em outras palavras, insistia em não se tornar familiar; um amigo, um duplo, um fraterno ao qual se pudesse oferecer como uma imagem de identificação. Ao se opor à própria assimilação, tornou-se unheimlich. Insistia em viver o presente, no aqui-e-agora desses pequenos momentos de (re)encontro. O barbeiro satisfazia-se, pois, 
de modo diferente: tinha lá outras formas de gozo e elas ameaçavam a forma como cada um sabia ser feliz.

Dado que vamos utilizar a palavra "gozo" com certa freqüência daqui para frente, julgamos necessário esclarecer o sentido que tem para Lacan. Uma melhor delimitação do conceito pode, a nosso ver, oferecer elementos adicionais de compreensão para o que foi dito linhas acima.

Para Lacan (1988), o gozo é o laço, o nó, entre a pulsão de vida e a pulsão de morte. Ao propor esta vinculação, Lacan rompe com a oposição, ainda presente em Freud, entre a libido (energia que mantém a vida) e as distintas formas de agressividade causadoras da autodestruição (morte). $\mathrm{Na}$ perspectiva psicanalítica, o gozo não se reduz ao orgasmo (satisfação sexual imediata), mas compreende formas de existência buscadas pelo homem para obtenção de prazer (felicidade). Busca essa que está inscrita na tensão permanente do conhecimento de sua própria finitude; situação de evidente desprazer e que inclui, também, a impossibilidade de assimilar, tornar seu o objeto de desejo. Tem-se aí uma outra antinomia: o outro com quem sou/penso ser feliz é e não é (m)eu. Ao gozo subjaz, pois, um ilusório sentimento de realização do desejo, para ser descoberto, mais adiante, que o Outro sempre nos escapa. Dito de outro modo, temos que nos haver permanentemente com sua falta e com o desejo de seu (re)encontro - não necessariamente sexual. ${ }^{16}$

Lacan estabelece então uma distinção essencial entre prazer e o gozo, residindo este na tentativa permanente de ultrapassar os limites do princípio do prazer. Esse movimento, ligado à busca da coisa perdida que falta no lugar do Outro, é causa de sofrimento; mas tal sofrimento nunca erradica por completo a busca do gozo. (Roudinesco e Plon, 1997, p. 300)

Para boa parte dos psicanalistas é necessário, ao se discutir este tema, trazer a questão da castração. Assim sendo, sem podermos nos alongar muito, deveríamos retornar a 1913, quando Freud (1974), em Totem e tabu, supõe que na horda humana primitiva o pai, líder supremo e possuidor de todas as fêmeas, foi morto pelos filhos a fim de que pudessem se fazer homens com as mulheres do chefe. Teria havido aí um prazer apenas possível, paradoxalmente, porque concomitante com o ambivalente desprazer causado pela morte e pela agressão ao pai, que tornou o gozo possível. Ter-se-ia aí a inauguração do tempo histórico de Édipo e, com ele, o medo de se ver castrado (ou de ser inutilizado como o pai), isto é, aparece um vivo e fantasioso temor de uma interdição cruel, pelo outro, ao próprio gozo. ${ }^{17}$ 
A interdição simbólica à posse do outro faz com que a energia ligada ao desejo reflua, retorne a mim-mesmo, tingido, agora, de amor e ódio amor e ódio pelo objeto interditado e por sua interdição; amor e ódio pela parcela de mim alienada nele. Se tomarmos esse enunciado como premissa, torna-se legítimo afirmar que para a psicanálise "ao ferir o outro, o sujeito não tem outro alvo a não ser ele mesmo, espelhado no outro" (Miller, 1997, p. 375).

Por conta do jogo dessa ambivalência é que, para Pontalis (1991), o racismo também pode ser entendido como um amor pelo próprio ódio.

(...) o fenômeno racista só surge quando o "estrangeiro" está na cidade. (...) O racismo encontra suas fontes na oposição entre próprio e estrangeiro (...) mas para expulsar é preciso antes ter ingerido. Só se vomita o que se engoliu. Não há corpo estranho senão dentro do próprio corpo. (...) Depois, já não há no racista oscilação entre atração e medo, essa fascinação confusa pelo estranho e estrangeiro. (...) O racista separa, cliva, há nele um amor pelo seu ódio. (P. 39-40)

Retornando à parábola inspiradora desta reflexão, o barbeiro personificava, acima de tudo, formas de ter prazer/ser feliz que aquelas pessoas não possuíam. Gozo estranho, como é o do casal de lésbicas surdas que decidiram fazer passar pelas próprias vaginas o sêmen de um homem geneticamente surdo. Estranho sentimento que nos despertam: não estariam elas nos dizendo que a felicidade pode ser algo mais intensamente simples? Que lá, onde pensamos ser correto nos entregarmos de forma normalmente heterossexual, não seria, mais nuamente, o espaço transgressor de íntima liberdade?

A questão é que não sabemos mais como ser livres - nossa liberdade também é definida por normas que, embora necessárias, são sempre arbitrárias e políticas (nada têm de naturais; são historicamente determinadas). E com base nelas, também julgamos a legitimidade moral de nosso próprio prazer.

Daí porque a raiva por essas duas mulheres, o desconforto que nos causam. São-nos (perturbadoramente) estranhas, embora nossa reação seja torná-las anormais, inseri-las em um espaço geométrico sem exterior e no qual, portanto, também habitamos e ajudamos a compor um conjunto de família (o espaço da norma). Insistentemente nos perguntamos: Quem são elas para quererem gozar em suas homossexualidades, fertilizando-se sem homens, e deles retirando apenas um suco - um extrato que insistimos em qualificar como anormal, 
geneticamente defeituoso? Como se não fosse nossa a definição de normalidade... Não bastassem tantas aberrações, tantas excentricidades juntas, elas gozam também juntas.

Segundo Julien (1995), o outro não nos conhece (porque também nos habita), mas nossa fantasia é a de que o outro quer sempre nos roubar o nosso gozo. Uma certa inveja também se aninha em nós: sorte a dele de ser tão feliz, ao passo que eu

vejo no Outro um gozo que provoca meu ódio, porque só posso ver nele alguém que me priva de algo e não um semelhante com quem possa me identificar. O ódio social nasce dessa suposição de um saber sobre o gozo do Outro. (Ibid., p. 58, grifo nosso)

Segundo Koltai (2000), para Lacan, "é a negação do estrangeiro que une os semelhantes; é a segregação que funda a fraternidade" (p. 98).

Nesta perspectiva, toda a sociedade teria, em sua origem, se baseado na segregação, condição para a existência de iguais. Iguais que, em nossos dias, compóem-se em grupos, propagam suas semelhanças (políticas, ideológicas etc.), insistentemente declaram suas diferenças com os outros grupos e arregimentam (mais) iguais (discípulos). Para os lacanianos, dessa igualdade se teria originado a fraternidade - laço real, ou simbólico, entre irmãos. A fraternidade seria, com base nessa premissa, efeito de um processo que tornou domésticas as diferenças, submetendo-as a um certo jogo de semelhanças. Por isso, e em certa medida, a fraternidade poderia ser entendida como o resultado de mecanismos racistas para a produção daquelas semelhanças. ${ }^{18}$

$\mathrm{O}$ estranho faria retornar tudo o que precisou ter sido deixado, ou alienado, para a composição desse desejo coletivo de se estar junto. Um corpo desejante não mais individual, mas social. Silenciamentos necessários, preço a ser pago por se conviver em sociedade. $\mathrm{O}$ estranho - personagem que nos provoca uma inquietante perturbação e, de algum modo, nos faz sentir, ao menos uma ou outra vez, sem que saibamos dizer bem por quê, certo mal-estar de vivermos em civilização.

Considerações finais

Pervertamos o bom sentido e desenvolvamos o pensamento fora do quadro ordenado das semelhanças. Então o pensamento aparece como uma verticalidade de intensidades, pois a intensidade, muito antes de ser graduada pela 
representação, é em si mesma uma pura diferença: diferença que se desdobra e repete, diferença que se contrai ou dilata, ponto singular que encerra ou solta, no seu agudo acontecimento, indefinidas repetições. (FOUCAULT)

Ao nos permitirmos admirar as linhas paralelas que compõem as abordagens foucaultiana e psicanalítica, em suas singularidades explicativas, supomos que, inevitavelmente, teremos que nos pôr a questão: o que o estranho teria a ver com o anormal?

Do ponto de vista teórico, julgamos que essas entidades não possuem a mesma natureza. E talvez o melhor que tenhamos a fazer é deixá-las em seus próprios campos de fabricação discursiva.

Os (a)normais fazem parte, de modo surdo, de uma mesma geometria. São elementos conhecidos, sempre explicáveis e demarcáveis na superfície de um território localizável e familiar - a norma.

De modo resumido, neste trabalho, a norma foi entendida como o conjunto de traços socialmente estabelecidos - uns mais explicita e meticulosamente que outros -, com base nos quais cada indivíduo, em uma sociedade, em um momento dado, pode apreciar o grau de distanciamento que guarda em relação a um outro, ou à sociedade como um todo, com referência a um aspecto determinado (peso, altura, audição, atividade sexual etc.). A norma permite, do mesmo modo, que cada um avalie a justeza do espaço que lhe foi atribuído em relação aos demais (questão de justiça e/ou de direito). Além disso, mais do que igualar, todo sistema normativo multiplica as desigualdades por meio de medidas sem sujeito: a norma reenvia cada ser a um dado, a uma craveira, a uma medida sem nome próprio para lhe conferir legitimidade (não há referência ao rei, ao messias, a Deus ou a qualquer personagem notável).

No espaço da norma não há exterioridade: tanto o anão como o gigante, tanto o retardado como o superdotado, tanto o deficiente visual como o vidente lhe são necessários, a fim de que possa completar toda a série de medidas, ascendentes e descendentes, a partir das quais cada indivíduo é posicionado e classificado em termos de proximidade ou de desvio. A norma permite, finalmente, que cada um possa ser o juiz e o pastor de si mesmo. O (a)normal é sempre um caso seu (Ewald, 2000).

A norma cumpre, igualmente, uma função política: é a dobradiça entre os poderes disciplinares (sobre corpos individuais que perfilam em instituiçôes) e o biopoder, uma 
nova tecnologia que se instala (na segunda metade do século XVIII), se dirige à multiplicidade dos homens, não na medida em que eles se resumem em corpos, mas na medida em que ela forma, ao contrário, uma massa global, afetada por processos de conjunto que são próprios da vida, que são processos como o nascimento, a morte, a produção, a doença etc. (Foucault, 2000, p. 289)

O biopoder dá amparo à bio-regulamentação pelo Estado moderno - cujas ações se voltam não por fazer morrer (caso da soberania medieval), mas em fazer viver, em encompridar o ciclo produtivo do que se chama vida humana coletiva.

E aí intervém o racismo de Estado - como meio de definir o que deve viver e o que deve morrer; ou as características genéticas a serem buscadas para uma maior otimização e alongamento da vida, em oposição a outras a serem emudecidas ou feitas morrer (os genes da surdez, por exemplo). É, também, o meio de justificar o genocídio de um Estado que deveria agora, paradoxalmente, fazer viver. "A morte do outro, a morte da raça ruim, da raça inferior (ou do degenerado, ou do anormal), é o que vai deixar a vida em geral mais sadia; mais sadia e mais pura" (idem, p. 305).

No caso do barbeiro, indivíduo sem passado, sem presença em gráficos, o racismo traduziu-se pela indiferença, por uma morte simbólica preexistente. De modo só na aparência contraditório, passou a ser um indivíduo para o Estado quando morreu biologicamente, quando foi lavrado seu óbito, registrada sua tumba; quando, finalmente, ganhou um nome próprio com sobrenome de família: Barbeiro de A. Nesse âmbito, não é de forma alguma estranho que o Estado tivesse rapidamente desistido de investigar sua morte, na ausência de um suspeito único.

O estranho tem a ver, fundamentalmente, com o desconhecido que somos nós para nós mesmos. O estranho tem uma territorialidade que escapa à localização; sua presença está fadada a ser apenas sentida, dado que não se submete à racionalidade de nenhum tipo. Sua ordem é a do desejo, portanto, seu espaço, paradoxalmente, é o da falta. Sua presença entre/em nós convoca-nos ou para a vida com seus jorros, ou para a morte - morte desse estranho em nós, tão insistente em ser saciado, tão aparentemente desinteressado em nos fazer voltar à unidade especular.

Por princípio lógico, o estranho jamais é assimilável (quando o é, deixa, obviamente, de sê-lo); matem-se lá, no lugar onde interditamos nosso gozo, ou antes, onde tivemos que o submeter a todos esses rituais necessários ao convívio civilizado. E por isso, quando o pressentimos no 
exterior, habitando corpos lésbicos, surdos ou do Barbeiro de A, incomodamo-nos tanto com ele: o repudiamos, o amamos, o desejamos intensamente e o odiamos sem medida (ambivalência), ou, finalmente, empenhamo-nos em torná-lo membro de família no espaço tranqüilizador e fraterno da norma.

Do ponto de vista conceitual, como dissemos anteriormente, as discussões sobre o anormal e o estranho são tributárias de abordagens teóricas incomensuráveis entre si. Todavia, cremos que, no que se refere à compreensão dos processos de exclusão social, são bastante produtivas. Para ambas, a exclusão se vincula ao racismo, à intolerância com o desigual.

Para Foucault (2000), o racismo foi antes uma ideologia científica - saberes sobre as chamadas degenerescências biológicas, raças, funcionamento normal etc. -, agenciada, depois, tanto pelos governos de direita como pelos de esquerda, para compor as estratégias de regulamentação e explicações de ações pelo Estado.

Para a psicanálise, o racismo advém de um extremo ódio e fascínio pela forma do gozo alheio - pelos modos como o outro quer/sabe ser feliz; formas de vidas outras que nos fazem ter a incômoda sensação de que talvez pudéssemos ser felizes de outros jeitos. Unheimlich.

Nas duas abordagens, todavia, há possibilidade de rupturas, da geração de espaços de transformação, de momento para o gozo. Foucault (1998a), por exemplo, insiste no traço positivo do poder, em sua infindável capacidade de criação, de produção de saberes e no fato de pertencer a todos e a ninguém ao mesmo tempo. É o "elemento" que constitui relaçóes sociais e resistência, mas, obviamente, produz opressões (respondendo, nos dois casos, a demandas históricas dadas). A questão, para ele, não é como acabar com o poder, mas decidirmos o que fazer com ele. Se decidirmos por mudanças, uma forma é pelo descaminho do próprio intelectual. "De que valeria a obstinação do saber se ele assegurasse apenas a aquisição dos conhecimentos e não, de certa maneira, e tanto quanto possível, o descaminho daquele que conhece?" (Foucault, 1998b, p. 13).

Mais além, no mesmo texto, o filósofo acrescenta:

Deve-se entender, com isso, práticas refletidas e voluntárias por meio das quais os homens não somente se fixam regras de conduta como também procuram se transformar, modificar-se em seu ser singular e fazer de sua vida uma obra que seja portadora de certos valores estéticos e responda a certos critérios de estilo. (Ibid., p. 15) 
Lembremos uma vez mais Deleuze (1992), que afirmou que "não cabe temer ou esperar, mas buscar novas armas" (p. 220). Se o biopoder permite a emergência do racismo de Estado, que leva a exclusão do diferente ao limite de sua eliminação pela morte, também é certo que a biopolítica permite a criação de novas ferramentas e instrumentos de luta, de novas armas que podem agenciar a eclosão das diferenças. Tudo depende de como se faz uso dos poderes e contrapoderes. Em lugar de cairmos no imobilismo de temer uma sociedade de controle - que se coloca para além do disciplinar, que aparentemente nos liberta das instituições, mas que se coloca como o "grande olho" que permite controlar os movimentos todos, no limite exercendo o poder de "deixar morrer", pelo exercício do racismo de Estado ou de outros mecanismos de apagamento das diferenças -, podemos assumir a perspectiva do exercício de contrapoderes, de fazer emergir novas possibilidades.

Em suma: escapar ao controle é possível. Hardt e Negri (2001) colocaram em epígrafe a Império uma frase da rockeira alternativa Ani DiFranco que se mostraria mais que profética: "Sabendo portá-la, toda ferramenta é uma arma". Por mais controle que se exerça sobre os indivíduos, a criatividade e a positividade do poder permitem a eclosão de possibilidades, da presença de diferenças.

Para a psicanálise, o gozo é uma conquista diária; e não inclui apenas a sensação prazerosa da conquista, mas um certo (des)conforto sempre presente - não há conquista total. E isso é efeito da impossibilidade fundante de sermos uno ou completos - estamos fadados a uma errância permanente. Em nossas viagens, do ponto de vista da psicanálise, é sempre produtivo conhecermos, nos limites do possível, esse território estrangeiro que somos nós para nós mesmos. Recurso interessante para podermos tirar vantagens em nossas lutas diárias pelo gozo ou para que possamos lembrar, ao menos vez ou outra, que o maior projeto da vida é existir. E existir é também poder permitir ao outro a liberdade de existência.

Recebido e aprovado em junho de 2002.

\section{Notas}

1. Decreto Presidencial no 3.298 de 20 de dezembro de 1999: Capítulo 1, artigo 3º, item 1, sobre a definição de deficiência: "Toda perda ou anormalidade de uma estrutura ou função psicológica, fisiológica ou anatômica que gere incapacidade para o desempenho de atividade, dentro do padrão considerado normal para o ser humano". 
2. Nosso reconhecimento à amiga Gladis Perlin com a qual exercitamos praticar - e não apenas defender - o direito ao gozo de ser como se é.

3. Unheimlich, palavra alemã traduzida usualmente como algo inquietante, sinistro ou medonho (Langenscheidts Taschenwörterbuch, 1995). Freud (1919/1976) fará um belíssimo ensaio sobre o tema, traduzido no Brasil como $O$ estranho, tradução imprecisa, pois, segundo Freud, não há em nossa língua um termo que possa compor o significado que unheimlich tem em alemão. Ver referência bibliográfica.

4. Sobre nosso apelo à metáfora matemática ou à compreensão com base na geometria, fazemos nossas as palavras de Veiga-Neto (2002, p. 8): "se a geometria serve como uma chave para compreender boa parte dos fenômenos e das rupturas que acontecem no mundo, é justamente porque tais fenômenos e rupturas são, de fato, espaciais - e também temporais -, pois eles e elas se dão a partir das condições de possibilidades que se estabelecem nas representações que se fazem acerca do espaço e do tempo (...). Por outro lado, se a tematização que eu desenvolvo é de cunho geométrico não é porque a geometria 'já estava aî', à espera da nossa leitura, mas sim porque a construção epistemológica que chamamos geometria se fez e se faz a partir de determinadas representaçōes sobre o espaço. Não importa, porque de nada adianta, especular metafisicamente se seria então o espaço aquilo que 'já estava aî'; o que importa é organizar um campo epistemológico - ao qual denominamos geometria - que funcione como uma 'matriz de fundo' dos sentidos atribuídos às nossas práticas espaciais".

5. Nosso agradecimento ao engenheiro Luís Shiguenobu Monobe pela orientação dada neste percurso. Luís mostrou-nos por que não deveríamos buscar uma outra figura geométrica em oposição à norma. Sugeriu-nos pensar a questão com base na teoria de conjuntos. Assim nos aconselhando, conduziu-nos à lógica das antinomias.

6. Epígrafe utilizada em: Caterina Koltai (2000), Política e psicanálise. O estrangeiro, São Paulo: Escuta.

7. Para situar o paradoxo, lembramos o caso clássico do barbeiro (B) da cidade que barbeia todos aqueles, e somente aqueles, que não se barbeiam a si mesmos. Poderia o barbeiro (B) ser incluído no conjunto daqueles que barbeiam a si mesmos? $\mathrm{Ou}$, sob a forma de enunciado matemático: o conjunto de todos os conjuntos que não são elementos deles mesmos é um elemento dele mesmo? Sobre essa questão, ver Boyer (1974). Devemos, todavia, apontar que, com base no Princípio de Incerteza de Heisenberg - segundo o qual não se pode conhecer simultaneamente, e com precisão, a velocidade e a posição de uma partícula subatômica -, talvez pudéssemos derivar a hipótese de que $\mathrm{B}$ tenha $\mathrm{x} \%$ de probabilidade de ser membro do conjunto W, em certo momento ou sob certas condiçôes. Isto quer dizer que não poderíamos nunca afirmar que sempre, e sob todas as condiçōes, B seja um elemento apartado do conjunto do qual faz parte. Para escapar desta provocativa incerteza, vamos considerar B nos momentos em que ele se comporta como um paradoxo. Dito de outro modo, no momento em que ele é e não é membro de W - na fração temporal em que não se sujeita à fixação.

8. Fremd é a palavra alemã para forasteiro, estranho, desconhecido, estrangeiro.

9. Em francês, ça designa também $I d$, uma das instâncias do aparelho psíquico estabelecida e descrita por Freud. Foucault joga, pois, com esse duplo sentido (Foucault, 1999, p. 27).

10. Metáfora emprestada de Wiesel (1982).

11. Esse curso foi publicado na França em 1997 e traduzido e publicado no Brasil em 1999, com o título Em defesa da sociedade, pela Editora Martins Fontes.

12. No caso da surdez, causou grande estranheza a decisão de um casal de lésbicas de ter um filho surdo por inseminação artificial. Um surdo, de quinta geração, da Universidade Gallaudet, foi escolhido como doador. A decisão de ambas tem recebido manifestações 
de repulsa por experts (revista Época, 15/4/2000) e comentários irônicos por jornalistas (leia-se o texto que consta na revista Veja de 17/4/2002). A questão que nos incomoda é pensar que algumas alteridades surdas possam não ser casos que a norma toma como seus.

13. Freud conta, para exemplificar, o episódio em que ele, numa viagem de trem, e por conta de um forte solavanco, viu adentrar em seu quarto-vagão um senhor de idade usando um gorro. A reação do psicanalista foi imediata: levantou-se para pedir ao velho que saísse. Ao dele se aproximar pôde notar, entretanto, que aquele senhor, por quem tinha sentido tanta antipatia, era a sua própria imagem refletida no espelho. Não era um velho que tinha entrado em seu quarto, tinha sido "apenas" a porta do banheiro espelhada que havia se aberto (Freud, 1919/1976).

14. Talvez como efeito da ativação inconsciente desse momento é que o quadro Las meninas, de Velásquez, cause sempre em nós grande fascínio.

15. Lacan cunhou uma terminologia que distingue outro e Outro. O Outro refere-se à presença de um terceiro, isto é, do inconsciente. Em 1955, afirmará que o Outro é aquilo de que se trata na função da fala. Nesse mesmo ano, dirá que o inconsciente é o discurso do Outro no qual o sujeito recebe, sob a forma invertida que equivale à promessa, sua própria mensagem esquecida. Com base em tal premissa, a linguagem não é o instrumento, mas a condição de produção de qualquer forma de comunicação. Ao discutir a diferença sexual, em 1975 (no seminário Mais, ainda), afirmará que homem e mulher se distinguirão entre si em relação a um significante de diferença: entre função fálica do gozo para o homem e o gozo suplementar feminino. O Outro, aqui, passa também a ser entendido como o lugar onde se inscreve a diferença irredutível para cada sujeito (ver Roudinesco e Plon, 1997). O Outro não se confunde, pois com o outro - o campo deste último é o da pura dualidade nos termos que usualmente a psicologia lhe confere. $\mathrm{Na}$ teoria, trata-se de pensar a alteridade com base na noção de alienação à imagem especular - o outro - e de designá-lo como um si-mesmo, ou como uma representação do eu marcada pela prevalência da relação dual com a imagem do semelhante (ibid., p. 559).

16. Adverte-nos Freud, já em 1932, em Novas conferências introdutórias sobre psicanálise (a de número XXXII), que os instintos sexuais são componentes extremamente plásticos do psiquismo, por "sua capacidade de alterar suas finalidades, sua capacidade de se substituírem, que permite uma satisfação instintual ser substituída por outra; e por sua possibilidade de se submeterem a adiamentos (...)" (Freud, 1976, p. 122).

$\mathrm{O}$ instinto/a pulsão em Freud (o termo preferido por ele é trieb) não é decorrente de um estímulo exterior, mas de uma excitação interior que convoca à satisfação. Cabe ao ego mediá-la, postergá-la, contê-la ou, valendo-se de sua plasticidade, transformá-la em realizações, não apenas com efeitos no plano do indivíduo (a satisfação em si mesma), mas também transferidas ao gozo coletivo por sublimação (os atos humanitários são um bom exemplo).

17. No caso da mulher, o medo do castigo, o sentimento de culpa, de amor e ódio pelo objeto interditado seguiria um processo afetivo similar, mas, por isto mesmo, não exatamente o mesmo do homem. Por exemplo, não existe para as mulheres o equivalente a um pai originário que escape à castração. O gozo do Outro, embora impossível também para as mulheres, não é atingido pela ameaça à castração. É radicalmente diferente, inacessível à compreensão do homem. Vale lembrar que Freud, como é sabido, e mais no final da vida, reconhece seu profundo desconhecimento sobre essa alteridade chamada "mulher". Isso porque, do ponto de vista masculino, a mulher é sempre uma espécie de estrangeira, goza de outros jeitos - um gozo sem limite, suplementar. Gozo incognoscível para e pelo homem e indizível pelas mulheres; sem dúvida, um elemento perturbador. Talvez isso explique por que ainda sejam tão comuns as práticas de excisão e "infabulação" 
de meninas em países muçulmanos da África; ou porque ainda, entre nós, são intensas as ações racistas contra as mulheres (ver Koltai, 2000). As idéias lacanianas sobre o gozo feminino vêm sendo utilizadas por psicanalistas, em geral mulheres, na elaboração de quadros para a compreensão da identidade feminina e em pesquisas centralizadas na noção de gênero (Roudinesco e Plon, 1997).

18. É preciso que se enfatize que, nesses termos, o conceito de fraternidade não recobre exatamente o de solidariedade.

Referências bibliográficas

BOYER, Carl Benjamin. História da matemática. São Paulo: Edgard Blücher/EDusp, 1974.

DELEUZE, Gilles. Conversaçôes. Rio de Janeiro: 34, 1992.

EWALD, François. Foucault, a norma e o direito. Lisboa: Vega, 2000.

FOUCAULT, Michel. Microfisica do poder. 13a ed. Rio de Janeiro: Graal, 1998 .

. História da sexualidade: $\mathrm{O}$ uso dos prazeres. $8^{\mathrm{a}}$ ed. Rio de Janeiro: Graal, 1998b.

História da sexualidade: A vontade de saber. $13^{a}$ ed. Rio de Janeiro: Graal, 1999.

. Em defesa da sociedade. São Paulo: Martins Fontes, 2000.

FREUD, Sigmund. "Cinco lições de psicanálise". In: Freud, Sigmund, Edição Standard Brasileira das Obras Psicológicas Completas de Sigmund Freud, volume XI, original em alemão escrito em 1910, Rio de Janeiro: Imago, 1970.

. "Totem e tabu". In: Freud, Sigmund, Edição Standard Brasileira das Obras Psicológicas Completas de Sigmund Freud, volume XIII, original em alemão publicado em 1913, Rio de Janeiro: Imago, 1974.

. "O estranho". In: Freud, Sigmund, Edição Standard Brasileira das Obras Psicológicas Completas de Sigmund Freud, volume XVII, original em alemão escrito em 1919, Rio de Janeiro: Imago, 1976.

"Conferência XXXII: Ansiedade e vida instintual". In: Freud, Sigmund, Edição Standard Brasileira das Obras Psicológicas Completas de Sigmund Freud, volume XXII, Rio de Janeiro: Imago, 1976. 
HARDT, Michael; NEGRI, Antonio. Império. Rio de Janeiro: Record, 2001.

JULIEN, Philippe. Pour lire Jacques Lacan. Paris: Seuil, 1990. . L'étrange jouissance du prochain. Paris: Seuil, 1995.

KOLTAI, Caterina. Política e psicanálise: O estrangeiro. São Paulo: Escuta, 2000 .

LACAN, Jacques. "Subversão do sujeito e dialética do desejo no inconsciente freudiano". In: LACAN, Jacques, Escritos, Rio de Janeiro: Zahar, 1998.

MILLER, Jacques-Alain. "Patologia da ética". In: Miller, Jacques-Alain, Lacan elucidado, Rio de Janeiro: Zahar, 1997.

PERLIN, Gladis. Surdez: Corpos habitáveis. Projeto de qualificação de doutorado, Programa de Pós-Graduação em Educação, Universidade Federal do rio Grande do Sul (UFRGS). Porto Alegre, 2002.

PONTALIS, Jean-Baptiste. "Uma cara que não agrada". In: PONTALIS, Jean-Baptiste, Perder de vista, Rio de Janeiro: Zahar, 1991.

REZENDE, Pedro Antonio Dourado. A crise nos fundamentos da matemática e a teoria da computação. Internet, http:// www.academicos.ubi.pt/home/guia-pagina/pdf/CAP_7.pdf, 2002

ROUDINESCO, Elisabeth; PLON, Michel. Dicionário de psicanálise. Rio de Janeiro: Zahar, 1997.

VEIGA-NETO, Alfredo. "Novas geometrias para o currículo e processos identitários". Atas do V Colóquio Sobre Questôes Curriculares e I Colóquio Luso-Brasileiro (Conferência de Abertura). Braga: Universidade do Minho, 2002.

WIESEL, E. Paroles d'étranger. Paris: Seuil, 1982. 